\title{
The Relationship between Organizational Learning Capability and Job Satisfaction
}

\author{
Seyyed Yaser Ebrahimian Jolodar \\ Department of Management, University of Isfahan, Hezarjerib Street, Isfahan, Iran \\ Tel: +98-937 6217899 E-mail: syebrahimian@yahoo.com
}

\begin{abstract}
Seyyed Rohollah Ebrahimian Jolodar
Department of Management, Islamic Azad University of Babol Branch, Babol, Iran

Tel: +98-9126406086_E-mail:Sr_ebrahimian_j@yahoo.com
\end{abstract}

Accepted: December 16, 2011 Published: December 5, 2012

doi:10.5296/ijhrs.v2i1.1242 URL: http://dx.doi.org/10.5296/ijhrs.v2i1.1242

\begin{abstract}
The effectiveness and productivity of an organization depends on its staff and if they don't be satisfied from their job, continues of living for such organization is impossible. One of the important factors which influence on job satisfaction, is an organizational learning capability (OLC). So, the purpose of this paper is to analyze the relationship between organizational learning capability and its dimensions (experimentation, risk taking, interaction with the external environment, dialogue and participative decision making) with job satisfaction. The population of this study was the employees of Tejarat Bank in Sari city, Iran and the sample number became 103. The data of job satisfaction gathered by a single item of Chiva and Alegre's (2008)questionnaire and for gathering the data of organizational learning capability, we used Chiva et al.'s (2007) OLC measurement instrument. For testing and analyzing the hypotheses, pearson correlation coefficient and multiple regression have been used.

The results of study show that there is a positive relationship between organizational learning capability with job satisfaction. Furthermore, the results revealed the five dimensions of organizational learning capability (experimentation, risk taking, interaction with the external environment, dialogue and participative decision making) had positive relationship with job satisfaction.
\end{abstract}

Keywords: Organizational learning capability, Job satisfaction, Staff 


\section{Introduction}

It is commonly said that "a happy worker is an effective one" and a happy worker should be satisfied with his job (Moghimi, 2006). Management specialists believe that the increase in job satisfaction leads to human resources development, and that satisfaction is directly related to productivity, so that higher satisfaction will bring about higher productivity and will consequently result in the elevation of the organization. In contrast, with the job satisfaction's lowering, not only administrative delinquencies will increase, but also much harm will be done to the organization (Amiri, 2010).

In fact, the effectiveness and productivity of an organization depends on the development and nurturing of its personnel. It is neither possible nor practical to increase the productivity of an organization without considering the optimal exploiting of the personnel capabilities. As is often the case, in attempting to define a construct belonging to the social sciences, there is no universally accepted definition of job satisfaction. Locke (1976), defined job satisfaction as a positive or pleasant emotional state resulting from a person's appreciation of his/her own job or experience (Demirtas, 2010). Locke's definition appears to be the most referenced and generally accepted description, characterizing the necessary component needed to depict what is meant by the broad construct of job satisfaction (Miller et al., 2009).

The conceptual domain of job satisfaction is broad, because it includes all characteristics of the job itself and the work environment, which employees find rewarding, fulfilling, and satisfying, or frustrating or unsatisfying (Güleryüz et al, 2008). There are many factors that affect job satisfaction and these factors make workers happy with their jobs and varies from one worker to another and from day to day (Lo and Ramayah,2011). One of these factors is organizational learning capability. The concept of organizational learning capability emphasizes the importance of the facilitating factors for organizational learning (Chiva et al, 2008). Organizational learning capability can also be defined as the ability of an organization to implement the appropriate management practices, structures and procedures that facilitate and encourage learning (Goh and Richards, 1997).

Most research analyzes the influence of certain job characteristics on job satisfaction. The most influential theory of how job characteristics affect people is Hackman and Oldham's job characteristics theory (Hackman and Oldman, 1980). On conducting further research, Jerez-Gomez et al. (2005) have identified four Organizational learning capability dimensions/constructs (Lam et al, 2008):

(1) Management commitment: management support and commitment to shared vision, organizational learning and developing culture for knowledge acquisition, creation and transfer; involved and facilitative leadership.

(2) Systems perspective: building a shared vision; system thinking - viewing the organization as a whole system.

(3) Openness and experimentation: a climate of openness for new ideas allowing individual knowledge to be constantly renewed, widened and improved; support experimentation in 
searching for innovative flexible solutions for problems.

(4) Knowledge transfer and integration: team work and learning, mechanism for knowledge spreading at an individual level and integrated into the organization.

Also, Chiva et al. (2007) in their research found that five facilitating factors appear to explain organizational learning capability: experimentation, risk taking, interaction with the external environment, dialogue and participative decision making.

Regarding the importance of these factors for effectiveness and productivity of human resources of an organization and in turn the effects of these factors on increasing the effectiveness and efficiency of the organization; we investigate the relationship between organizational learning capabilities with job satisfaction. For this purpose, we used (Chiva et al.'s 2007) five facilitating factors of organizational learning capability and studied the relations between these factors (experimentation, risk taking, interaction with the external environment, dialogue and participative decision making) and job satisfaction.

\section{Literature review}

\subsection{Organizational learning capability}

An organizational learning has to promote and nurture its capability to learn for improvement and innovation. Recent studies (Santos-Vijande et al., 2005) show that organizational learning capability is an indirect but very useful measure of organizational learning. Organizational learning capability can be defined as the ability of an organization to implement the appropriate management practices, structures and procedures that facilitate and encourage learning (Goh and Richards, 1997). Also, it can be defined as an intrinsic ability of an organization because of which the organization creates, enriches, and utilizes knowledge to outperform its competitors in terms of its competitiveness and performance (Limpibunterng \& Johri, 2009).

Chiva et al., (2007) identified five essential facilitating factors of organizational learning: experimentation, risk taking, interaction with the external environment, dialogue and participative decision making.

Experimentation: can be defined as the degree to which new ideas and suggestions are attended to and dealt with sympathetically (Nevis et al., 1995). Nevis et al. (1995) consider that experimentation involves trying out new ideas, being curious about how things work, or carrying out changes in work processes.

Risk taking: can be understood as the tolerance of ambiguity, uncertainty, and errors. Sitkin (1996) goes as far as to state that failure is an essential requirement for effective organizational learning, and to this end, examines the advantages and disadvantages of success and errors. 
Interaction with the external environment: is defined as the scope of relationships with the external environment. The external environment of an organization is defined as factors that are beyond the organization's direct control of influence (Bapuji and Crossan, 2004).

Dialogue: is defined as a sustained collective inquiry into the processes, assumptions, and certainties that make up everyday experience (Isaacs, 1993). Some authors (Dixon, 1997) understand dialogue to be vitally important to organizational learning.

Participative decision making: refers to the level of influence employees have in the decision-making process (Cotton et al., 1988). Organizations implement participative decision making to benefit from the motivational effects of increased employee involvement, job satisfaction and organizational commitment (Scott-Ladd and Chan, 2004).

In this study we analyzed the relations between organizational learning capabilities with job satisfaction. Specially, we studied the relations between five essential facilitating factors of organizational learning capabilities (experimentation, risk taking, interaction with the external environment, dialogue and participative decision making) with job satisfaction.

\subsection{Job satisfaction}

Job satisfaction is defined as "the extent to which people like (satisfaction) or dislike (dissatisfaction) their jobs" (Spector, 1997). This definition suggests that job satisfaction is a general or global affective reaction that individuals hold about their job. On the other hand, Demirtas (2010) defined job satisfaction as a positive emotional feeling, a result of one's evaluation towards his or her job experience by comparing between what he or she expects from his or her job and what he or she actually gets from it. Job satisfaction is one of the important factors playing role in job accomplishment and results to greater effectiveness, efficiency and productivity as well as personal satisfaction feelings (Mosaddegh-rad, 2004).

When employees are not satisfied, they tend to shift and look for satisfaction elsewhere (May \& Ramaya, 2011). Researchers in the past suggested that a person's job satisfaction comes from how he or she feels is more important than the fulfillment or unfulfillment of his or her needs (Locke, 1976). When employees are not satisfied, they tend to shift and look for satisfaction elsewhere. Ting (1997) contended that job characteristics such as pay, promotional opportunity, task clarity and significance, and skills utilization, as well as organizational characteristics such as commitment and relationship with supervisors and co-workers have significant effects on job satisfaction(Lo \& Ramayah,2011).

\subsection{Organizational learning capability and job satisfaction}

Most research analyzes the influence of certain job characteristics on job satisfaction. The most influential theory of how job characteristics affect people is Hackman and Oldham's job 
characteristics theory (Hackman and Oldman, 1980). Research suggests that job satisfaction, as a work-related outcome, is determined by organizational culture and structure (Egan et al., 2004). However, few studies of job satisfaction appear to incorporate any of the five conceptual dimensions that define organizational learning capability. In this point, they describe some of the most relevant antecedents of job satisfaction linked to organizational learning. Bussing et al. (1999) detect a connection between job satisfaction and employee engagement.

According to Kim (2002), participative management that incorporates effective supervisory communication can increase job satisfaction. Wagner and LePine (1999) conducted a meta-analysis and find significant impacts of job participation and work performance on job satisfaction. Daniels and Bailey (1999) conclude that participative decision making increases the level of job satisfaction. Eylon and Bamberger (2000) report that empowerment has a significant impact on job satisfaction. Johnson and McIntey (1998) find that the measures of culture most strongly related to job satisfaction are empowerment, involvement, and recognition. Gaertner (2000) states that leadership behaviors related to inspiring teamwork, challenging tradition or enabling others have been shown to have significant effects on job satisfaction. Griffin et al. (2001) report that the extent of teamwork is positively related to perceptions of job autonomy, which in turn affects job satisfaction.

\section{Research Model and Hypotheses}

Based on literature review of job satisfaction and organizational learning capability, we proposed a conceptual model based on Chiva et al.'s (2007) model. They suggested that there are five essential facilitating factors of organizational learning capabilities which effects on job satisfaction. So, in this research we studied the relations between organizational learning capability and its dimensions with job satisfaction. Figure 1 . shows the research conceptual model.

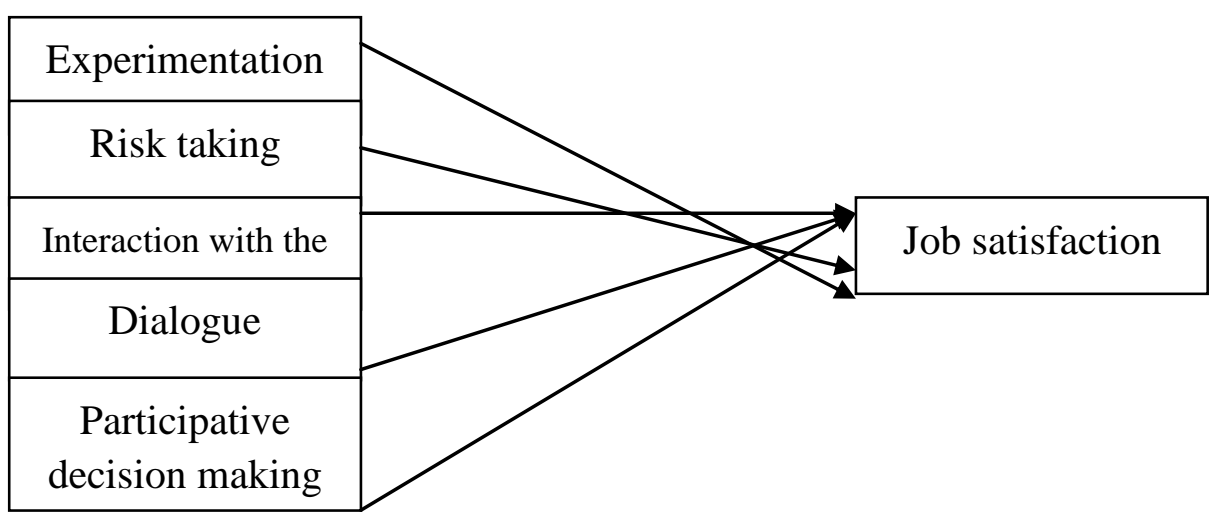

Figure 1. Research conceptual model 
So, according to the research conceptual model, we suggested following hypotheses:

Main hypothesis: Organizational learning capability is positively related to the job satisfaction.

Sub hypotheses:

1- Experimentation is positively related to the job satisfaction.

2- Risk taking is positively related to the job satisfaction.

3- Interaction with the external environment is positively related to the job satisfaction.

4- Dialogue is positively related to the job satisfaction.

5- Participative decision making is positively related to the job satisfaction.

\section{Research Methodology}

This research can be categorized as descriptive research based on the method of obtaining the considered data. Since these data are made for studying the distribution of statistical population characteristics through sampling of population, this research is a survey done on the basis of cross sectional method.

\subsection{Statistical Population and Sample}

The statistical population of this study was the staff of Tejarat Bank in Sari, Iran and the sample number became 103. The variance of answers from the primary sample have obtained .0 .51 , and by putting it in formula, the reliability level $(\alpha)$ was 95 percent, and estimate accuracy (E) was 0.1 , the sample size was 103 . But, 5 gathered questionnaires from responders were not complete and useful for analysis. So, we have done our analysis by using 98 completed questionnaires. The results of the primary sample show that Cronbach alpha $(\alpha)$ index is 0.76 that indicate a good reliability.

\subsection{Information Gathering Tool}

The data gathering instrument was a questionnaire. For gathering the data of organizational learning capability we used Chiva et al.'s (2007) OLC measurement instrument which consists of 10 questions and measured by five-point Likert-type scale.

Also, for gathering the data of job satisfaction, we have used a single item of Chiva and Alegre (2008). The measure of staff's job satisfaction was derived from answers to the question "How much do you like your job?" expressed on a seven-level response scale ranging from "dislike it very much" to "like it very much". A single item to measure job satisfaction is used by Staw and Ross (1985), Ganzach (1998) and Chiva and Alegre (2008). 


\section{Research Findings}

\subsection{Hypotheses Testing}

For testing and analyzing the hypotheses, pearson correlation coefficient and multiple regression have been used.

Main hypothesis: Organizational learning capability is positively related to the job satisfaction.

Table1. Pearson correlation coefficient between organizational learning capability and job satisfaction

\begin{tabular}{|c|c|c|c|c|c|}
\hline Correlation coefficient & \multicolumn{4}{|c|}{ Job satisfaction } & Test Result \\
\hline \multirow{2}{*}{$\begin{array}{l}\text { Organizational learning } \\
\text { capability }\end{array}$} & $\mathrm{R}$ & $\mathrm{R}^{2}$ & Adjusted $\mathrm{R}^{2}$ & Sig & \multirow[b]{2}{*}{ Supported } \\
\hline & 0.49 & 0.24 & 0.23 & 0.000 & \\
\hline
\end{tabular}

According to Table1., correlation coefficient between organizational learning capability and job satisfaction $(0.49)$ is significant with $(\mathrm{sig}<0.05)$. So, there is a significant relationship between organizational learning capability and job satisfaction. Also, R Squares is 0.24. It means that 24 percent of job satisfaction variance can be explained by organizational learning capability.

Hypothesis 1. Experimentation is positively related to the job satisfaction.

Table 2. Pearson correlation coefficient between experimentation and job satisfaction

\begin{tabular}{|c|c|c|c|c|c|}
\hline Correlation & \multicolumn{4}{|c|}{ Job satisfaction } & Test Result \\
\hline \multirow[b]{2}{*}{ Experimentation } & $\mathrm{R}$ & $\mathrm{R}^{2}$ & Adjusted $\mathrm{R}^{2}$ & Sig & \multirow[b]{2}{*}{ Supported } \\
\hline & 0.59 & 0.35 & 0.34 & 0.000 & \\
\hline
\end{tabular}

According to Table 2., correlation coefficient between experimentation and job satisfaction $(0.59)$ is significant with $(\mathrm{sig}<0.05)$. So, there is a significant relationship between experimentation and job satisfaction $\left(\mathrm{H}_{1}\right.$ is supported). Also, $\mathrm{R}$ Squares is 0.35 . It means that 35 percent of job satisfaction variance can be explained by experimentation.

Hypothesis 2. Risk taking is positively related to the job satisfaction. 
Table 3. Pearson correlation coefficient between risk taking and job satisfaction

\begin{tabular}{|c|c|c|c|c|c|}
\hline Correlation coefficient & \multicolumn{4}{|c|}{ Job satisfaction } & Test Result \\
\hline \multirow[b]{2}{*}{ Risk taking } & $\mathrm{R}$ & $\mathrm{R} 2$ & Adjusted $\mathrm{R}^{2}$ & Sig & \multirow[b]{2}{*}{ Supported } \\
\hline & 0.51 & 0.26 & 0.25 & 0.000 & \\
\hline
\end{tabular}

According to Table 3., correlation coefficient between risk taking and job satisfaction $(0.51)$ is significant with (sig <0.05). So, there is a significant relationship between risk taking and job satisfaction $\left(\mathrm{H}_{2}\right.$ is supported). Also, $\mathrm{R}$ Squares is 0.26 . It means that 26 percent of job satisfaction variance can be explained by risk taking.

Hypothesis 3. Interaction with the external environment is positively related to the job satisfaction.

Table 4. Pearson correlation coefficient between interaction with the external environment and job satisfaction

\begin{tabular}{|c|c|c|c|c|c|}
\hline Correlation & \multicolumn{4}{|c|}{ Job satisfaction } & Test Result \\
\hline & $\mathrm{R}$ & $\mathrm{R}^{2}$ & Adjusted $\mathrm{R}^{2}$ & Sig & \multirow[b]{2}{*}{ Supported } \\
\hline $\begin{array}{l}\text { Interaction with the } \\
\text { external environment }\end{array}$ & 0.23 & 0.05 & 0.04 & 0.010 & \\
\hline
\end{tabular}

According to Table 4., correlation coefficient between interaction with the external environment and job satisfaction (0.23) is significant with (sig <0.05). So, there is a significant relationship between interaction with the external environment and job satisfaction $\left(\mathrm{H}_{3}\right.$ is supported). Also, $\mathrm{R}$ Squares is 0.05 . It means that 5 percent of job satisfaction variance can be explained by interaction with the external environment.

Hypothesis 4. Dialogue is positively related to the job satisfaction.

Table 5. Pearson correlation coefficient between dialogue and job satisfaction

\begin{tabular}{|c|c|c|c|c|c|}
\hline Correlation & \multicolumn{4}{|c|}{ Job satisfaction } & Test Result \\
\hline \multirow[b]{2}{*}{ Dialogue } & $\mathrm{R}$ & $\mathrm{R}^{2}$ & Adjusted $\mathrm{R}^{2}$ & Sig & \multirow[b]{2}{*}{ Supportec } \\
\hline & 0.20 & 0.04 & 0.03 & 0.026 & \\
\hline
\end{tabular}


According to Table 5., correlation coefficient between dialogue and job satisfaction is significant $(0.20)$ with ( $\mathrm{sig}<0.05$ ). So, there is a significant relationship between dialogue and job satisfaction $\left(\mathrm{H}_{4}\right.$ is supported). Also, $\mathrm{R}$ Squares is 0.04 . It means that 4 percent of job satisfaction variance can be explained by dialogue.

Hypothesis 5. Participative decision making is positively related to the job satisfaction.

Table 6. Pearson correlation coefficient between participative decision making and job satisfaction

\begin{tabular}{|c|c|c|c|c|c|}
\hline Correlation & \multicolumn{4}{|c|}{ Job satisfaction } & Test Result \\
\hline \multirow[b]{2}{*}{$\begin{array}{l}\text { Participative } \\
\text { decision making }\end{array}$} & $\mathrm{R}$ & $\mathrm{R}^{2}$ & Adjusted $\mathrm{R}^{2}$ & Sig & \multirow[b]{2}{*}{ Supported } \\
\hline & 0.41 & 0.17 & 0.16 & 0.000 & \\
\hline
\end{tabular}

According to Table 6., correlation coefficient between participative decision making and job satisfaction is significant $(0.41)$ with ( $\mathrm{sig}<0.05)$. So, there is a significant relationship between participative decision making and job satisfaction $\left(\mathrm{H}_{5}\right.$ is supported). Also, $\mathrm{R}$ Squares is 0.17 . It means that 17 percent of job satisfaction variance can be explained by participative decision making.

\section{Conclusions}

It is proved that the effectiveness and productivity of an organization depends on the development and nurturing of its staff. It is neither possible nor practical to increase the productivity of an organization without considering the optimal exploiting of the staff's capabilities. Job satisfaction is one of the important factors playing role in job accomplishment and results to greater effectiveness, efficiency and productivity as well as personal satisfaction feelings. When employees are not satisfied, they tend to shift and look for satisfaction elsewhere. Human resources are the most valuable resources in an organization and assuring workers' job satisfaction is one of the most important factors of professional accomplishment and organizational efficiency and productivity. Understanding the conditions under which emotional intelligence influences job satisfaction will help to determine its potential importance for organizations, specifically through the lenses of the new competencies management literature. On the other hand, it will relate important and new concepts being used by organizations, such as competencies management and organizational learning.

So, in this study we investigate the relationship between organizational learning capabilities with job satisfaction. For this purpose, we used (Chiva et al.'s 2007) five facilitating factors of organizational learning capability and studied the relations between these factors (experimentation, risk taking, interaction with the external environment, dialogue and 
participative decision making) and job satisfaction. The results of study show that there is a significant positive relationship between organizational learning capability and its dimensions with job satisfaction. Furthermore, the results revealed that experimentation and after it, risk taking had the most effects on job satisfaction. The role of organizational learning capability can be explained by the fact that emotionally intelligent individuals tend to work in conditions that propitiate their emotional and social abilities (teamwork, risk taking, dialogue, participation, etc.), and consequently they are likely to have higher levels of job satisfaction. Organizational learning capability might thus be considered as a stimulating working context, where emotionally intelligent people can develop their competencies and achieve satisfaction. When seeking to improve employee job satisfaction, practitioners should take into account working conditions such as organizational learning capability and its dimensions.

\section{References}

Amiri. M., Khosravi. A., Mokhtari.,A .A . (2010) . Job satisfaction and its influential factors. Journal of Research in Health Science,10(1):42-46. Bapuji, H. and Crossan, M. (2004). From raising questions to providing answers: reviewing organizational learning research, Management Learning, Vol. 35 No. 4, pp. 397-417. http://dx.doi.org/10.1177/1350507604048270.

Bussing, A., Bissels, T., Fuchs, V. and Perrar, K. (1999) .A dynamic model of work satisfaction: qualitative approaches, Human Relations, Vol. 52 No. 8, pp. 999-1028. http://dx.doi.org/10.1177/001872679905200802.

Chiva, R. (2004) .The facilitating factors for organizational learning in the ceramic sector, Human Resource Development International, Vol. 7 No. 2, pp. 233-49. http://dx.doi.org/10.1080/1367886042000243817.

Chiva, R., Alegre, J. and Lapiedra, R. (2007) .Measuring organizational learning capability among the workforce, International Journal of Manpower, Vol. 28 No. 3, pp. 224-42. http://dx.doi.org/10.1108/01437720710755227.

Chiva, R., Alegre, J. (2008). Emotional intelligence and job satisfaction: the role of organizational learning capability, Personnel Review, Vol. 37 No. 6, 2008 pp. 680-701. http://dx.doi.org/10.1108/00483480810906900.

Cotton, J.L., Vollrath, D.A., Foggat, K.L., Lengnick-Hall, M.L. and Jennings, K.R. (1988). Employee participation: diverse forms and different outcomes, Academy of Management Review, Vol. 13 No. 1, pp. 8-22.

Daniels, K. and Bailey, A. (1999). Strategy development processes and participation in decision making: predictors of role stressors and job satisfaction, Journal of Applied Management Studies, Vol. 8 No. 1, pp. 27-42. 
Demirtas,Z,.(2010).Teachers' job satisfaction levels, Procedia Social and Behavioral Sciences ,9 , 1069-1073. http://dx.doi.org/10.1016/j.sbspro.2010.12.287.

Dixon, N. (1997). The hallways of learning, Organizational Dynamics, Vol. 25 No. 4, pp. 23-34. http://dx.doi.org/10.1016/S0090-2616(97)90034-6.

Egan, T.M., Yang, B. and Bartlett, K.R. (2004). The effects of organizational learning culture and job satisfaction on motivation to transfer learning and turnover intention, Human Resource Development Quarterly, Vol. 15 No. 3, pp. 279-301. http://dx.doi.org/10.1002/hrdq.1104.

Eylon, D. and Bamberger, P. (2000). Empowerment cognitions and empowerment acts: recognizing the importance of gender, Group \& Organization Management, Vol. 25, pp. 354-73. http://dx.doi.org/10.1177/1059601100254003.

Gaertner, S. (2000). Structural determinants of job satisfaction and organizational commitment in turnover models, Human Resource Management Review, Vol. 9 No. 4, pp. 479-93. http://dx.doi.org/10.1016/S1053-4822(99)00030-3.

Ganzach, Y. (1998). Intelligence and job satisfaction, Academy of Management Journal, Vol. 41 No. 5, pp. 526-39. http://dx.doi.org/10.2307/256940.

Goh, S. and Richards, G. (1997). Benchmarking the learning capability of organizations, European Management Journal, Vol. 15 No. 5, pp. 575-83. http://dx.doi.org/10.1016/S0263-2373(97)00036-4.

Griffin, M.A., Patterson, M.G. and West, M.A. (2001). Job satisfaction and teamwork: the role of supervisor support, Journal of Organizational Behavior, Vol. 22, pp. 537-50. http://dx.doi.org/10.1002/job.101.

Hackman, J.R. and Oldman, G.R. (1980). Work Redesign, Addison-Wesley, Reading, MA.

Isaacs, W. (1993). Dialogue, collective thinking, and organizational learning, Organizational Dynamics, Vol. 22 No. 2, pp. 24-39. http://dx.doi.org/10.1016/0090-2616(93)90051-2.

Jerez-Gomez, P., Cespedes-Lorente, J. and Valle-Cabrera, R. (2005). Organizational learning capability: a proposal of measurement, Journal of Business Research, Vol. 58, pp. 715-25. http://dx.doi.org/10.1016/j.jbusres.2003.11.002.

Johnson, J.J. and McIntey, C.L. (1998). Organization culture and climate correlates of job satisfaction. Psychological Reports, Vol. 82, pp. 843-50. 
Kim, S. (2002). Participative management and job satisfaction: lessons for management leadership, Public Administration Review, Vol. 62, pp. 231-41. http://dx.doi.org/10.1111/0033-3352.00173.

Lam, M.Y., Poon, K.K. \& Chin, K.S.(2008). An organizational learning model for vocational education in the context of TQM culture, International Journal of Quality \& Reliability Management, Vol. 25 No. 3, pp. 238-255. http://dx.doi.org/10.1108/02656710810854269.

Lo, M.C. \& Ramayah, T.(2011).Mentoring and job satisfaction in Malaysian SMEs, Journal of Management Development, Vol. $30 \quad$ No. 4, 2011 pp. 427-440. http://dx.doi.org/10.1108/02621711111126891.

Locke, E. A. (1976). The nature and causes of job satisfaction. In M. D. Dunette (Ed.), Handbook of industrial and organizational psychology. Chicago: RandMcNally.

McEnrue, M. P., Groves, K. S., \& Shen, W. (2009). Emotional intelligence development: leveraging individual characteristics, Journal of Management Development, Vol. 28 No. 2, pp. 150-174. http://dx.doi.org/10.1108/02621710910932106.

Mosaddegh-rad, AM. (2004) . Investigation of the relationship between personnel's job satisfaction and management style of managers in Isfahan hospitals, Isfahan University of Medical Sciences: Research report.

Nevis, E., DiBella, A.J. and Gould, J.M. (1995). Understanding organization learning systems, Sloan Management Review, Vol. 36 No. 2, pp. 73-85.

Santos-Vijande, M., Sanzo-Perez, M., Alvarez-Gonzalez, L. and Vazquez-Casielles, R. (2005). Organizational learning and market orientation: interface and effects on performance, Industrial Marketing Management, Vol. $34 \quad$ No. 3 , pp. 187-93. http://dx.doi.org/10.1016/j.indmarman.2004.08.004.

Scott-Ladd, B. and Chan, C.C.A. (2004). Emotional intelligence and participation in decision-making: strategies for promoting organizational learning and change, Strategic Change, Vol. 13 No. 2, pp. 95-105. http://dx.doi.org/10.1002/jsc.668.

Spector, P.E. (1997). Job Satisfaction, Sage, Thousand Oaks, CA.

Staw, B.M. and Ross, J. (1985). Stability in the midst of change: a dispositional approach to job attitudes, Journal of Applied Psychology, Vol. 70, pp. 469-80. http://dx.doi.org/10.1037/0021-9010.70.3.469.

Wagner, J.A. and LePine, J.A. (1999). Effects of participation on performance and satisfaction: additional meta-analytic evidence, Psychological Reports, Vol. 84, pp. 719-25. 
